\title{
Residual Analysis Applied to S-N Data of a Surface Rolled Cast Iron
}

\author{
Omar Malufa*, Marcelo Tadeu Milan, Dirceu Spinelli, Mariano E. Martínez ${ }^{\mathrm{b}}$ \\ a Departmentt of Materials, Aeronautics and Automotive Engineering \\ ${ }^{\mathrm{b}}$ Department of Structures Engineering School of São Carlos, University of São Paulo, \\ 13566-590 São Carlos - SP, Brazil
}

Received: August 11, 2004; Revised: April 5, 2005

\begin{abstract}
Surface rolling is a process extensively employed in the manufacture of ductile cast iron crankshafts, specifically in regions containing stress concentrators with the main aim to enhance fatigue strength. Such process hardens and introduces compressive residual stresses to the surface as a result of controlled strains, reducing cyclic tensile stresses near the surface of the part. The main purpose of this work was to apply the residual analysis to check the suitability of the S-N approach to describe the fatigue properties of a surface rolled cast iron. The analysis procedure proved to be very efficient and easy to implement and it can be applied in the verification of any other statistical model used to describe fatigue behavior. Results show that the conventional S-N methodology is able to model the high cycle fatigue behavior of surface rolled notch testpieces of a pearlitic ductile cast iron submitted to rotating bending fatigue tests.
\end{abstract}

Keywords: surface rolling, fatigue, residual stress, statistical model, residual analysis

\section{Introduction}

Ductile cast iron is produced through the addition of a metallic alloy containing $\mathrm{Fe}-\mathrm{Si}-\mathrm{Mg}$ to a base cast iron in order to produce nodular graphite, instead of flake graphite as found in grey cast irons ${ }^{1}$. This process allows the manufacturing of materials with improved mechanical strength and ductility which are extensively used in the fabrication of mechanical parts such as crankshafts. Strength and ductility are dependent on the matrix microstructure ${ }^{2}$. Depending on the chemical composition and heat treating, the matrix can be either ferritic, pearlitic, ferritic-pearlitic, bainitic, martensitic or austenitic ${ }^{3}$. Size and distribution of the graphite nodules in the matrix are also important to the mechanical properties ${ }^{4}$.

The fatigue strength of a cast part depends not only on the microstructure and chemical composition, but also on the surface finishing and geometry of the part. Dimension gradients and notches are stress concentrators which are prone to fatigue crack nucleation and if they cannot be avoided in the design of part, they must undergo special treatments ${ }^{5}$. For example, in order to eliminate sharp ends in automotive crankshafts, notches are machined with a minimum radius which is subsequently surface rolled $^{6}$. The main aim of such procedure is to reduce notch sensitivity in these regions and thus reducing fatigue crack nucleation probability in critical regions of mechanical parts ${ }^{7}$.

Although statistical models are largely used in fatigue data analysis, a verification of the suitability of the model is not always checked. The main purpose of this work was to apply the residual analysis to check the suitability of the conventional S-N approach to describe the fatigue properties of a surface rolled cast iron. Additionally, the authors expect that this paper is capable of introducing a step-bystep procedure for the implementation of the residual analysis to any statistically significant model.

\section{Residual Analysis}

\subsection{S-N curve}

The most usual way of representing fatigue results is the S-N curve, where $\mathrm{S}$ is the applied stress amplitude or the maximum ap- plied stress and $\mathrm{N}$ is the number of cycles for failure. In this curve, $\mathrm{N}$ values are plotted on the abscissa axis and $\mathrm{S}$ values are plotted on the ordinate axis ${ }^{8}$. Generally, these results are plotted in bi-logarithmic scale resulting in a curve which can be expressed by:

$$
\log (\mathrm{N})=\mathrm{A}+\mathrm{B} \log (\mathrm{S})
$$

where $\mathrm{A}$ and $\mathrm{B}$ are the regression coefficients to be determined.

Although Equation 1 is normally used to model fatigue life, the number of cycles for failure, $\mathrm{N}$, may depend not only on $\mathrm{S}$ values but also on other independent variables which can be statistically significant. In the particular case of surface rolled parts, the presence of surface compressive residual stresses can potentially affect the model. Cyclic loading may cause residual stress relaxation which is closely related to the level of applied stresses. Experimental work and theoretical models have shown that higher applied loads are likely to cause both higher relaxation rate and higher relaxation levels ${ }^{9,10}$. Thus, there could be non-linear relationships such as quadratic and exponential that would better describe the fatigue properties of surface rolled parts. In this sense, these considerations raise a few questions:

1. How to identify that the assumed independent variables of the model are statistically significant?

2. How to check that the proposed model is adequate to describe the fatigue behavior of the material?

Normally, the answer to these questions is obtained by using a residual analysis of the statistical model.

\subsection{Statistical model}

A statistical model is a mathematic model which contains a random error with a specific probability distribution. Usually, this model is used to predict the value of one of the variables when the other is known, under specific conditions ${ }^{11}$. In a statistical model, two or more variables are correlated using regression analysis equations. These equations are mainly used to predict the dependent variable, $\mathrm{Y}$, as a function of the independent variable, $\mathrm{X}$. In the analysis, some assumptions are necessary ${ }^{12,13}$ : 
The independent variable, $\mathrm{X}$, is considered free of errors because $\mathrm{X}$ is not a random variable.

There is a linear relationship between $\mathrm{Y}$ e $\mathrm{X}$ and the statistical model that relates $\mathrm{Y}_{\mathrm{i}}$ to $\mathrm{X}_{\mathrm{i}}$ is given by:

$$
Y_{i}=A+B X_{i}+\varepsilon_{i}
$$

for $i=1, \ldots, n$, where $n$ is the number of observations.

In Equation 2, A and B are unknown constants to be estimated and they are called parameters of the regression model. $\varepsilon_{\mathrm{i}}$ is a random value, denominated random error. The value of $\varepsilon_{\mathrm{i}}$ for any observation will depend on both a possible error of measurement and other variables different from $X_{i}$ that were not measured that could affect $Y_{i}$. The values of $\varepsilon_{i}$ are random variables, assuming the following assumptions:

1. The average of $\varepsilon_{\mathrm{i}}$ values is equal to zero and its variance, $\sigma^{2}$, is unknown and constant for $1 \leq \mathrm{i} \leq \mathrm{n}$.

2. $\varepsilon_{\mathrm{i}}$ values are not correlated.

3. The distribution of $\varepsilon_{\mathrm{i}}$ values is normal for $1 \leq \mathrm{i} \leq \mathrm{n}$.

Second and third assumptions imply that $\varepsilon_{\mathrm{i}}$ values are mutually independent.

The regression line is, in general, unknown and therefore must be estimated through the sampling data. In the particular case where the regression of $\mathrm{Y}$ in relation to $\mathrm{X}$ is linear, the best fit line can be written as:

$$
\hat{\mathrm{Y}}_{\mathrm{i}}=\hat{\mathrm{A}}+\hat{\mathrm{B}}_{\mathrm{i}}
$$

where the symbol "caret" $(\wedge)$ denotes estimate (estimator), $\hat{A}$ and $\hat{B}$ are determined by the least squares method and $\hat{Y}_{i}$ are the estimated values of $Y_{i}$ using Equation 3 and the differences between $Y_{i}$ and $\hat{Y}_{i}$ shall be minimum. Generally, these differences are known as residuals, i.e., errors associated to the predicted values of $\mathrm{Y}_{\mathrm{i}}$ corresponding to each $\mathrm{X}_{\mathrm{i}}$ value and which can be calculated through the following expression:

$$
\hat{e}_{i}=Y_{i}-\hat{Y}_{i}
$$

\subsection{Verifying the adequacy of the linear model}

One of the most important tools for the verification of the adequacy of a regression model is the residual analysis. Values obtained by Equation 4 are the base for this procedure ${ }^{13}$. In this analysis, it is possible to check if the assumptions about the residuals of the model, given by Equation 1, are satisfied, i.e., to verify that equal variance, normality and independence are accomplished. The validity of such assumptions can be verified through graphical analysis.

In order to evaluate the assumption of equal variance, in general, the residuals are plotted against the estimated $\hat{Y}$. This assumption will be valid if the dispersion of residuals in such plot does not reveal any obvious pattern. In Figure 1, a valid graph to accept the suitability of the model is presented, where the residuals are randomly distributed with equal variance.

If a funnel shape graph is obtained (Figure 2), the variance increases, indicating non - constancy. When inconstancy is found, data in both axes should be plotted in a logarithmic scale in order to stabilize the variance.

The verification of residuals normality can also be analysed by plots, such as normal score and normal probability graphs. In these graphs, the assumption of normality is valid if the points in the graph are localized approximately along a straight line. However, in case of doubt, the linearity can be confirmed using a statistical test of normality, such as the one proposed by Shapiro and Francia ${ }^{14}$.

The assumption of independence can be checked by a graph of residuals against time (order of data collection). If the residuals are randomly distributed along the time axis, the independence assump- tion will be valid. On the other hand, if a cyclic pattern, for example, is present in the graph, it means that the data is not independent.

Another tool to analyse the suitability of the regression model is the coefficient of determination, $\mathrm{R}^{2}$. However, the residual analysis must always be performed because it allows identifying the lack of correlation and indicates possible adequate models. The coefficient of determination is given by:

$$
R^{2}=\frac{\sum_{i=1}^{n}\left(\hat{Y}_{i}-\bar{Y}\right)^{2}}{\sum_{i=1}^{n}\left(Y_{i}-\bar{Y}\right)^{2}}
$$

where the symbol "overbar" ( ${ }^{-}$) denotes average.

Once the suitability of the model given by Equation 2 is checked, it is possible to infer and create prediction intervals more reliably and hence to estimate fatigue life (or stress levels for a given life) with greater confidence.Within the range of experimental points, the prediction interval $100(1-\alpha) \%$ for a particular variable $\mathrm{Y}_{\mathrm{o}}$ is estimated by:

$$
\hat{Y}_{0} \pm t_{\alpha / 2} \hat{\varphi} \sqrt{\frac{1}{n}+\frac{\left(X_{e}-\bar{X}\right)^{2}}{S_{x x}}}
$$

For points outside the testing interval, the prediction interval is given by:

$$
\hat{Y}_{0} \pm t_{\alpha / 2} \hat{\varphi} \sqrt{1+\frac{1}{n}+\frac{\left(X_{e}-\bar{X}\right)^{2}}{S_{x x}}}
$$

where,

$$
\hat{\mathrm{Y}}_{0}=\hat{\mathrm{A}}+\hat{\mathrm{Bx}}_{\mathrm{e}}
$$

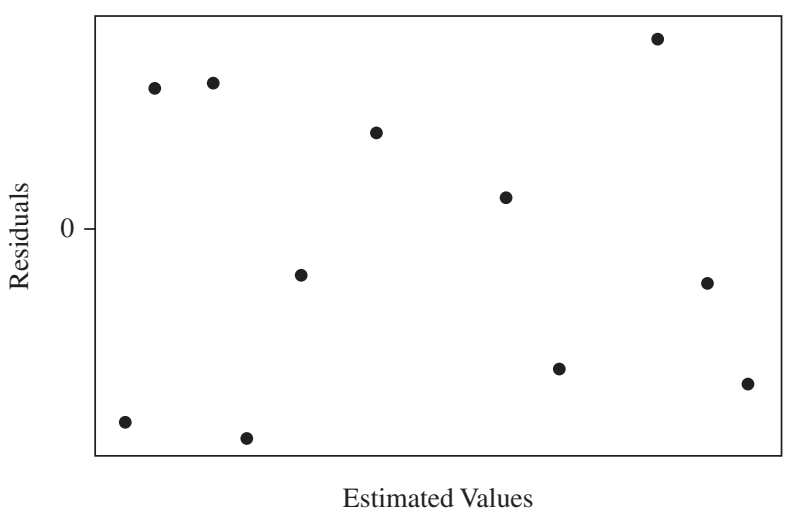

Figure 1. Example of a graph of residuals $\left(\hat{\mathrm{e}}_{\mathrm{i}}\right)$ against the estimated values $\left(\hat{\mathrm{Y}}_{\mathrm{i}}\right)$ when the regression model is adequate.

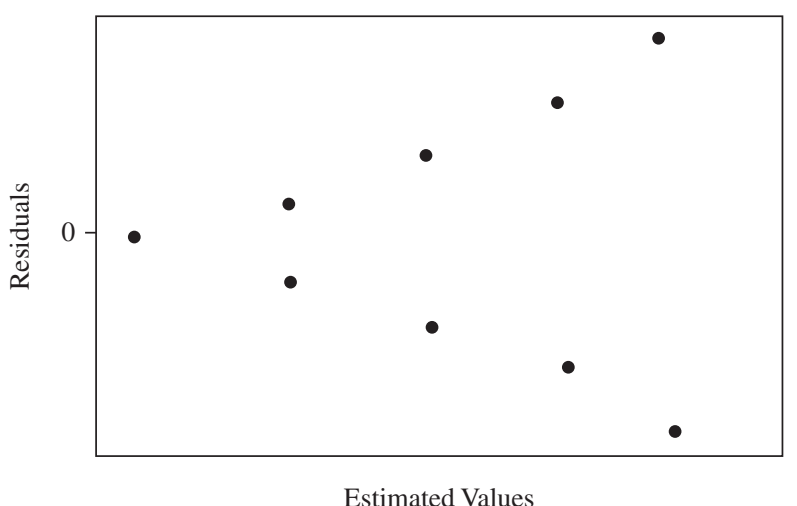

Figure 2. Example of a graph of residuals $\left(\hat{\mathrm{e}}_{\mathrm{i}}\right)$ against the estimated values $\left(\hat{\mathrm{Y}}_{\mathrm{i}}\right)$ showing that the variance is non-constant. 


$$
\begin{aligned}
& \hat{\varphi}^{2}=\frac{\sum_{i=1}^{n}\left(Y_{i}-\hat{Y}_{i}\right)^{2}}{n-2} \\
& S_{x x}=\left\{n \sum_{i=1}^{n} X_{i}^{2}-\left(\sum_{i=1}^{n} X_{i}\right)^{2}\right\} / n
\end{aligned}
$$

and $X_{e}$ is a specific value of $X$ outside the interval of observed values, $\alpha$ is the significance level, $t_{(\alpha / 2)}$ is determined from a $t$ Student distribution with n-2 degrees of freedom and $\hat{\varphi}$ is $\sqrt{\left(\hat{\varphi}^{2}\right)}$.

\section{Experimental Procedures}

In this work, bending rotating high cycle fatigue tests were performed in surface rolled notch testpieces of ductile cast irons. The matrix microstructure presented on average $85 \%$ of pearlite and $15 \%$ of ferrite; more than $80 \%$ of the graphite nodules were type I and II, according to ASTM A2474. Average results of tensile tests indicated that the material is a 100-70-03 class material, according to ASTM A536 ${ }^{15}$. All tests were performed in room temperature and in as-cast condition. Average chemical composition is presented in Table 1.

For the bending rotating fatigue tests, notched testpieces were manufactured according to ASTM E466 ${ }^{16}$, as seen in Figure 3. The notch was surface rolled prior to fatigue testing. Bending rotating fatigue tests were performed according to ASTM E468 ${ }^{17}$, under a frequency of $92 \mathrm{~Hz}$. Testpieces were considered non-failed when lives exceeded $10^{7}$ cycles. The number of stress levels and the number of testpieces tested at each stress level were determined according to ASTM E739 ${ }^{8}$, in order to obtain a replication between $75 \%$ and $88 \%$. The apparatus used for surface rolling the notches consists basically of 3 rollers disposed at $120^{\circ}$ in relation to testpiece axis, as seen in Figure 4.

Rolling load was applied to the notch by a hardener roller which had a diameter of $15 \mathrm{~mm}$, thickness of $5 \mathrm{~mm}$ and curvature radius of $1.3 \mathrm{~mm}$. The other support rollers consisted of a $26 \mathrm{~mm}$ diameter sphere. The hardener roller was fixed to an apparatus used for surface rolling of crankshafts which was adapted for this work.

The apparatus was fixed to the tool post of a lathe and load was applied through the movement of the tool post perpendicularly to the testpiece axis which had both ends fixed to the lathe. Load was measured by a $10 \mathrm{kN}$ load cell attached to the support rollers which were fixed to the base of the lathe. Load readings were acquired by a Transdutec-TMDE model digital reader. Testpiece notches were surface rolled under an applied load of $2.39 \mathrm{kN}$, frequency of $50 \mathrm{rpm}$ and 250 revolutions.

Table 1. Average chemical analysis results (in weight \%).

\begin{tabular}{cccccccc}
\hline $\mathrm{C}$ & $\mathrm{Si}$ & $\mathrm{Mn}$ & $\mathrm{Cr}$ & $\mathrm{Cu}$ & $\mathrm{P}$ & $\mathrm{S}$ & $\mathrm{Mg}$ \\
\hline 3.56 & 2.36 & 0.45 & 0.016 & 0.46 & 0.046 & 0.010 & 0.050 \\
\hline
\end{tabular}

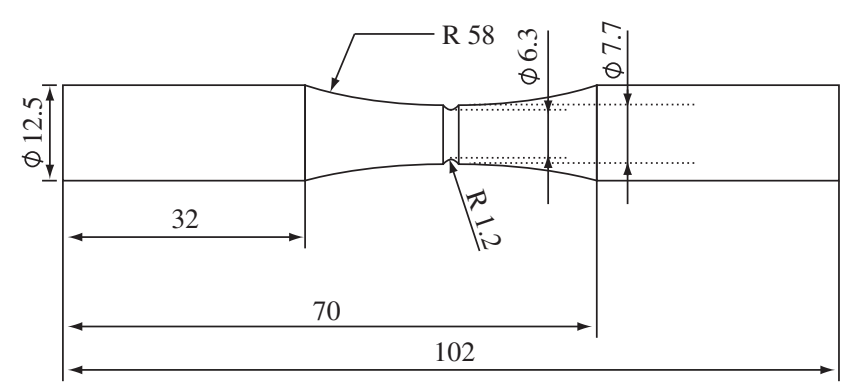

Figure 3. Notched testpiece for bending rotating fatigue tests.

\section{Results and Discussion}

Results of the fatigue tests are presented in Table 2. All data presented refer to fractured testpieces. Data analysis of the number of cycles for failure of the testpieces initiates with the verification of
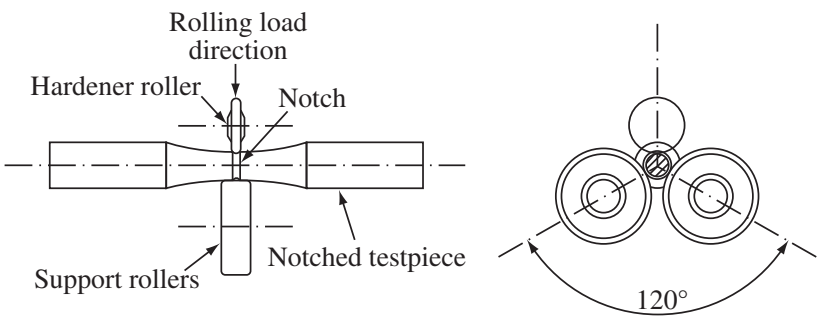

(a)

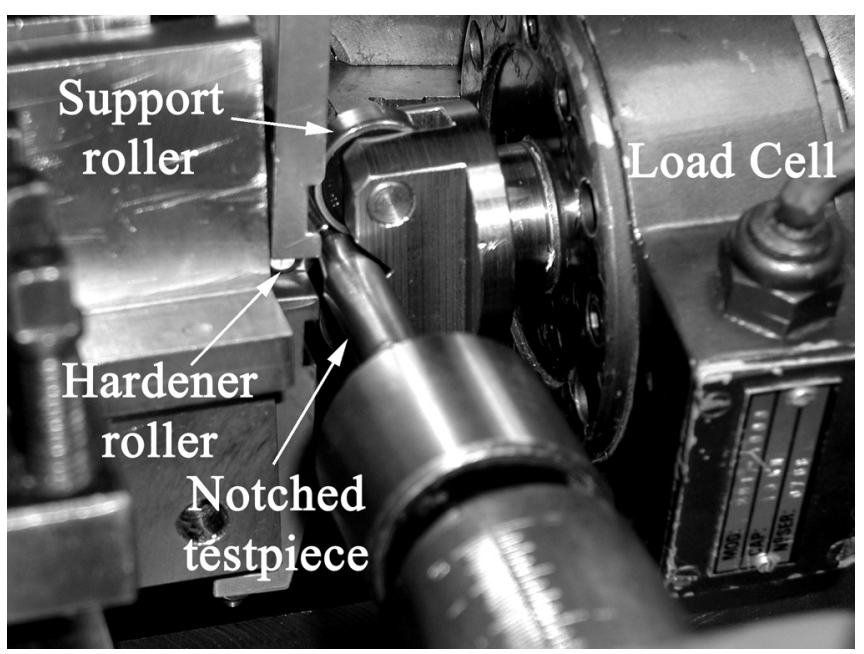

(b)

Figure 4. Surface rolling apparatus: a) Schematic representation; b) photograph of the equipment.

\begin{tabular}{|c|c|}
\hline $\mathrm{S}(\mathrm{MPa})$ & $\mathrm{N}$ (cycles for failure) \\
\hline 550 & 117900 \\
\hline 550 & 148000 \\
\hline 550 & 260700 \\
\hline 550 & 264300 \\
\hline 550 & 272100 \\
\hline 525 & 222700 \\
\hline 525 & 249500 \\
\hline 525 & 312900 \\
\hline 525 & 367400 \\
\hline 525 & 1143900 \\
\hline 500 & 2319900 \\
\hline 500 & 1350000 \\
\hline 500 & 2607300 \\
\hline 500 & 1290100 \\
\hline 500 & 695300 \\
\hline 475 & 902800 \\
\hline 475 & 4892000 \\
\hline 475 & 1499900 \\
\hline 475 & 4234300 \\
\hline
\end{tabular}

Table 2. S and $\mathrm{N}$ values for surface rolled notch testpieces of ductile cast iron. 
the suitability of the model through the residual analysis. Estimated values and the residuals are obtained by Equation 3 and Equation 4, respectively. In this work, all residual analysis calculations were performed using a statistics software package.

The graph of normal scores against the residuals was used to check if the normal distribution is attained (Figure 5). It is observed that the data results approximately in a straight line, indicating that the residuals of the model in principle follow a normal distribution. However, when the graph of residuals against estimated values is plotted (Figure 6), it is possible to observe a funnel shape which indicates an increase in variance. Therefore, the equal variance assumption is not attained and a modification of the model is necessary.

Therefore, a logarithmic conversion of both $\mathrm{S}$ and $\mathrm{N}$ data is performed to check if the assumptions of equal variance and normality are obtained. As seen in Figure 7, the variance is constant. In Figure 8, the residuals can be approximately fitted by a straight line and the assumption of normality is attained. Hence, from the residual analysis it can be concluded that the stress level $\mathrm{S}$ is the only independent variable statistically significant and the model given by Equation 2 is adequate to describe the high cycle fatigue properties of surface rolled notch testpieces of the ductile cast iron of the present work. It is important to emphasize that if the assumptions of equal variance and normality were not attained even after the logarithmic transformation of both $\mathrm{S}$ and $\mathrm{N}$ scales, either the proposed model

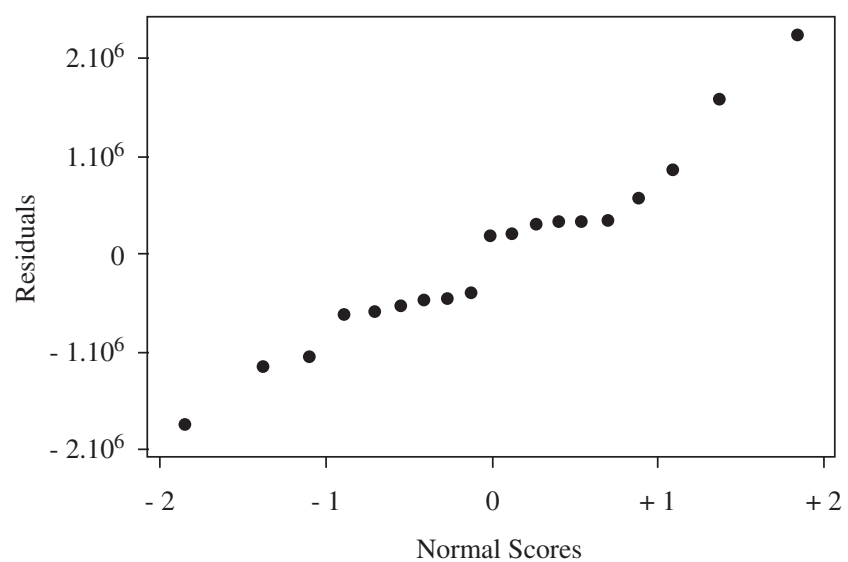

Figure 5. Graph of residuals against normal scores values for rolled notch testpieces.

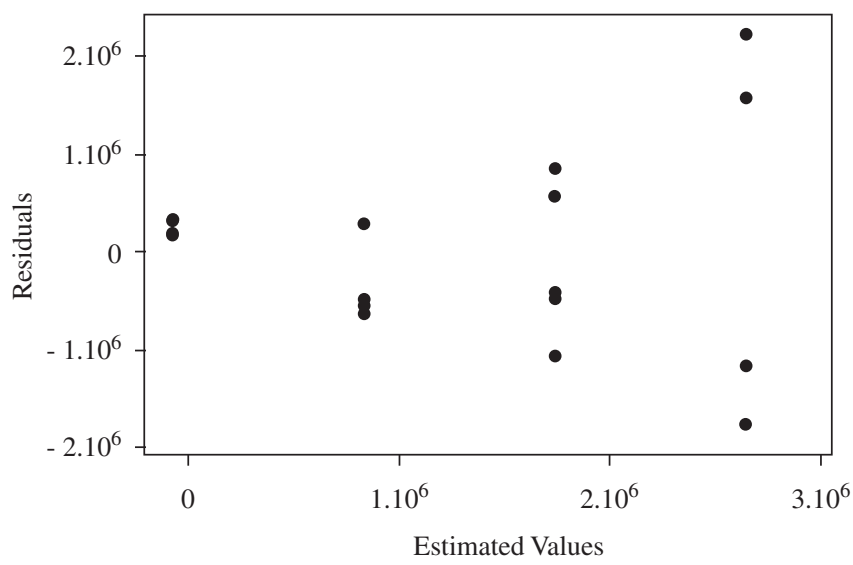

Figure 6. Graph of residuals against estimated values for rolled notch testpieces. would have to be described by a different mathematical function or an additional statistically significant independent variable would have to be included in the model.

Once the suitability of the model is checked, it is possible to obtain the linear relationship between $\log \mathrm{N}$ and $\log \mathrm{S}$, as presented in Equation 11:

$$
\log (\mathrm{N})=54.6-18.0 \log (\mathrm{S})
$$

This model shows a standard deviation (s) of 0.2632 and a coefficient of determination $\left(\mathrm{R}^{2}\right)$ of $73.6 \%$ for $\mathrm{n}=19$ observations. Additionally, Table 3 presents the regression coefficients of Equation 11 with their respective standard deviation $s$ and $t_{0}$ ratio.

Figure 9 presents the S-N curve with a prediction interval of $95 \%$. Observe that in this curve the independent variable $\mathrm{S}$ is plotted in the ordinate axis while the dependent variable $\mathrm{N}$ is presented in the abscissa as usually found in conventional S-N graphs ${ }^{8}$. Equation 11

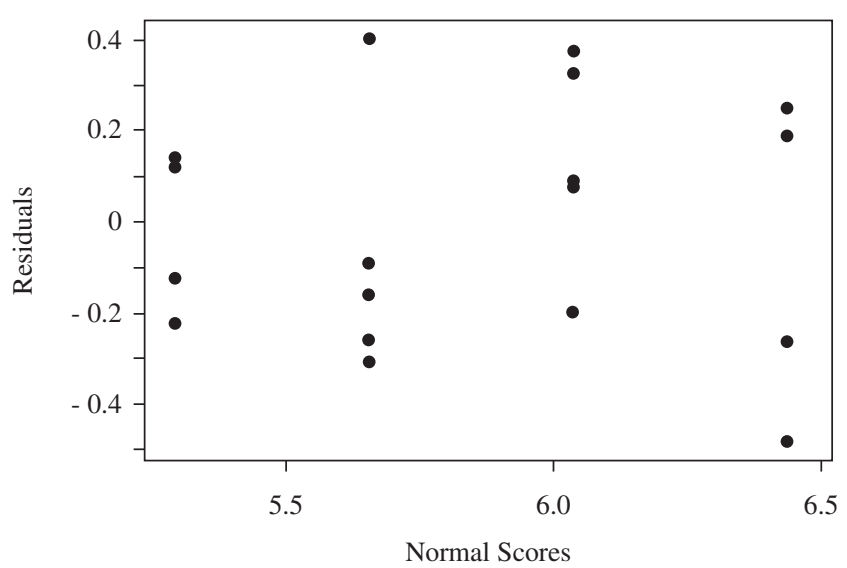

Figure 7. Graph of residuals against estimated values for rolled notch testpieces (after applying logarithmic scales).

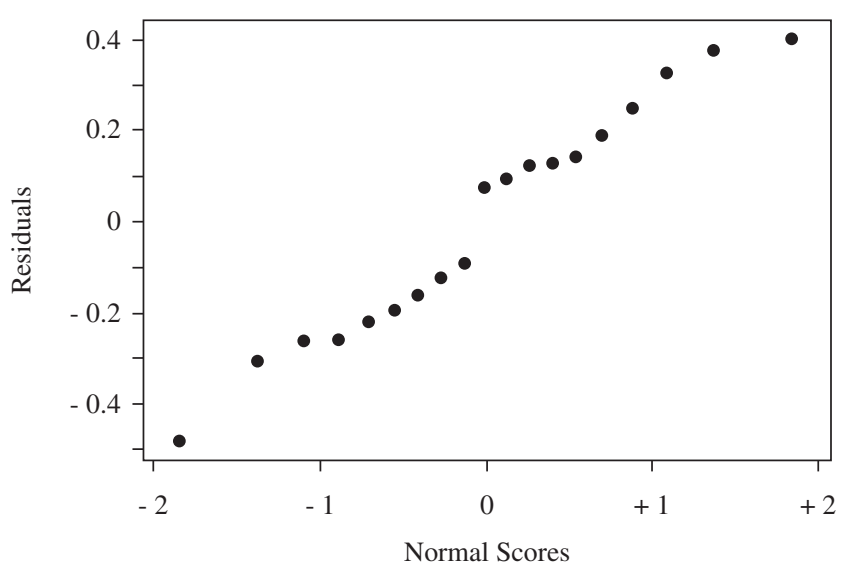

Figure 8. Graph of residuals against normal scores for rolled notch testpieces (after applying logarithmic scales).

Table 3. Regression coefficients of Equation 7 with their respective standard deviations $\mathrm{s}$ and to ratios.

\begin{tabular}{ccc}
\hline Regression Coefficients & $\mathrm{s}$ & to \\
\hline $\mathrm{A}=54.599$ & 7.079 & 7.71 \\
$\mathrm{~B}=-17.992$ & 2.611 & -6.89 \\
\hline
\end{tabular}




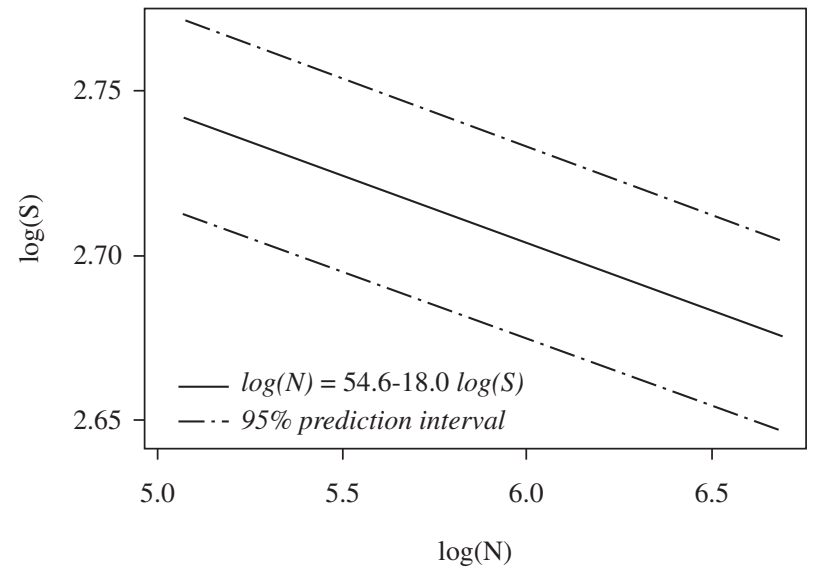

Figure 9. S-N curve and 95\% prediction intervals for the surface rolled notch testpieces.

allows estimating accurately both the number of cycles for failure for a given applied stress level and the corresponding 95\% prediction interval. However, in some cases it is necessary to determine the stress level at which failure will take place for a given number of cycles, in other words, it is necessary to obtain the endurance limit. According to Equation 11, for $2.10^{6}$ cycles for example, the endurance limit for the notch surface rolled testpieces of the ductile cast iron of the present work is approximately $483 \mathrm{MPa}$ and the $95 \%$ prediction interval ranges from $459.8 \mathrm{MPa}$ to $522.7 \mathrm{MPa}$.

\section{Conclusions}

A residual analysis procedure was successfully applied to analyze high cycle fatigue data of surface rolled notch testpieces of a pearlitic ductile cast iron tested under bending rotating fatigue. The procedure proved to be very simple and easy to implement and it can be applied to any statistical fatigue model. The residual analysis showed that the conventional bi-logarithmic model of S-N data is able to describe the fatigue properties of the cast iron, showing an endurance limit of approximately $483 \mathrm{MPa}$ at $2.10^{6}$ cycles calculated according to the regression equation obtained from the model.

\section{References}

1. Labrecque C, Gagné M. Ductile iron: Fifty years of continuous development. Canadian Metallurgical Quarterly. 1998; 37(5):343-378.
2. QIT-Fer et Titane Incorporation. A Design Engineer's Digest of Ductile Iron. $7^{\text {th }}$ ed. Montreal: Rio Tinto Iron \& Titanium, Inc., 1990.

3. Guesser WL, Hilário DG. Ferros fundidos nodulares perlíticos. Fundição e Serviços. 2000; 11(95):46-55.

4. ASTM: A247-98. Standard Test Method for Evaluating the Microstructure of Graphite in Iron Castings. Annual Book of ASTM standards. West Conshohocken: American Society for Testing and Materials, 2001.

5. Maluf O. Influência do roleteamento no comportamento em fadiga de um ferro fundido nodular perlítico. [MSc Thesis]. São Carlos: University of São Paulo; 2002.

6. Daniewicz SR, Moore DH. Increasing the bending fatigue resistance of spur gear teeth using a presetting process. International Journal of Fatigue. 1998; 20(7):537-542.

7. QIT-Fer et Titane Incorporation. Ductile Iron Data for Design Engineers. Montreal: Rio Tinto Iron \& Titanium, Inc., 1990:75-80.

8. ASTM: E739-98. Standard Practice for Statistical Analysis of Linear or Linearized Stress-Life (S-N) and Strain-Life ( $\varepsilon$-N) Fatigue Data. American Society for Testing and Materials, Annual Book of ASTM standards, vol.03.01, Philadelphia, 2000.

9. Farrahi GH, Lebrun JL, Couratin D. Effect of shot peening on residualstress and fatigue life of a spring steel. Fatigue and Fracture of Engineering Materials and Structures. 1995; 18(2):211-220.

10. Zhuang WZ, Halford GR. Investigation of residual stress relaxation under cyclic load. International Journal of Fatigue. 2001; 23:S31-S37, 2001

11. Martínez ME. Desenvolvimento de um modelo estatístico para aplicação no estudo de fadiga em emendas dentadas de madeira. [PhD Thseis]. São Carlos: University of São Paulo; 2001.

12. Chatterjee S, Price B. Regression Analysis by example. New York: John Wiley \& Sons, Inc., 1977.

13. Draper NR, Smith H. Applied Regression Analysis. New York: John Wiley \& Sons, Inc., 1998.

14. Shapiro SS, Francia RS. Approximate analysis of variance test for normality. Journal of the American Statistical Association. 1972; 67(337):215-223.

15. ASTM: A536-98. Standard Specification For Ductile Iron Castings. American Society for Testing and Materials, Annual Book of ASTM standards, vol.01.02, Philadelphia, 2000.

16. ASTM: E466-96. Standard Practice for Conducting Force Controlled Constant Amplitude Axial Fatigue Tests of Metallic Materials. Annual Book of ASTM standards. West Conshohocken: American Society for Testing and Materials, 2000.

17. ASTM: E468-98. Standard Practice for Presentation of Constant Amplitude Fatigue Tests Results for Metallic Materials. Annual Book of ASTM standards. West Conshohocken: American Society for Testing and Materials, 2000. 